\title{
Minimally Invasive Sacroiliac Joint Arthrodesis: Experience in a Prospective Series with 24 Patients
}

Vicente Vanaclocha-Vanaclocha*, Francisco Verdú-López, Moisés Sánchez-Pardo, Laurabel Gozalbes-Esterelles, Juan Manuel Herrera, Marlon Rivera-Paz and Débora Martínez-Gómez

Department of Neurosurgery, Hospital General Universitario de Valencia, Spain

"Corresponding author: Vanaclocha-Vanaclocha V, Department of Neurosurgery, Consorcio Hospital General Universitario de Valencia, Tres Cruces Av, Valencia 46014, Spain, Tel: 0034 658652886, E-mail: vvanaclo@hotmail.com

Rec date: Aug 11, 2014, Acc date: Oct 06, 2014, Pub date: Oct 08, 2014

Copyright: (c) 2014 Vanaclocha VV, et al. This is an open-access article distributed under the terms of the Creative Commons Attribution License, which permits unrestricted use, distribution, and reproduction in any medium, provided the original author and source are credited.

\begin{abstract}
Background: Sacroiliac (SI) joint pain conservative treatments show poor outcomes. Hypothesis: surgical treatment will show better results.

Patients and methods: Prospective series: 24 patients undergoing SI fusion after failure of medical treatment and showing temporary relief with SI infiltration. Period: Nov 2009-July 2013. Gender: 9/15. 11 cases bilaterally (all ). Age: $32-71$ years (mean 47.4 years). Height: $161-178 \mathrm{~cm}$ (mean $168.2 \mathrm{~cm}$ ). Weight: $56-84 \mathrm{~kg}$ (mean $68.4 \mathrm{~kg}$ ). Etiology: 12 degenerative/spontaneous, 7 fall on buttocks, 3 coincident with lumbar disc and 2 with lumbar posterolateral fusion. Exclusion criteria: ankylosing spondylitis, osteitis condensans ilii, sacro-iliac joint arthropaty. Demographics, analgesics and NSAID's consumption, incidence and severity of complications, clinical outcome using a visual analog scale (VAS) for pain, Oswestry Disability Index (ODI) and time to returning to work were collected postoperatively at 1,3 and 6 months, and then at six months interval until last follow-up.
\end{abstract}

Results: Follow-up: 1-4.5 years (mean 23.3 months). No intra-operative or post-operative major complications. No blood transfusions. Patients stayed over-night, and discharged next morning. No crutches used. Time to returning to work: 47.4 days (range 30-67 days). Post-op: marked reduction in VAS and analgesic consumption (preop 8.7, post-op 1 month 3.2, 3 months 2.8, 6 months post-op 2.1, 12 months 1.7, 18 months 1.7, 2 years 1.9, 21/2 years $1.8,3$ years 2.0 , at $3 \frac{1}{2}$ years $2.1,4$ years 2.1 and $4 \frac{1}{2} 2.1$ ). Mean ODI scores improved from 54.1 preoperatively to $23.9,21.2,20.4$ and 14.3 at $1,3,6$ and 12 months postoperatively, and 15.1, 15.5 15.8, 16.0, 16.1, 16.3 and 16.3 at $1 \frac{1}{2}, 2,2 \frac{1}{2}, 3,3 \frac{1}{2}, 4$ and $4 \frac{1}{2}$ years $(p<.001) .1$ year post-op 22/24 patients would undergo the procedure again.

Conclusion: Percutaneous SI joint arthrodesis is effective and safe to treat chronic SI joint pain.

Keywords: Arthrodesis; Chronic low back pain; Minimally invasive surgery; Sacroiliac joint; Sacroiliac joint arthrodesis; Sacroiliac joint dysfunction; Sacroiliac joint pain

\section{Introduction}

In patients with chronic axial Low Back Pain (LBP), the Sacroiliac (SI) joint is the pain generator in an estimated $15 \%$ to $25 \%$ of cases [1]. Many patients with SI joint pain are currently misdiagnosed or not diagnosed at all, leading to an improper treatment with a bad outcome. It is, therefore, essential to be aware that the SI joint can be a source of pain to diagnose and to treat it accordingly [2]. SI joint pain is currently treated with several treatment modalities. Among all the conservative options available a recent review showed poor short-term and long-term results from intra-articular or peri-articular injections with steroids or botulin toxin, pulsed radiofrequency, and conventional radiofrequency neurotomy, with slightly better results with cooled radiofrequency neurotomy [3]. In recent years several groups have reported excellent results with SI joint fusion [4-18]. With the hypothesis that surgical treatment will show excellent results we report a prospective series of 24 patients, after following a diagnostic and therapeutic algorithm $[19,20]$.

\section{Patients and Methods}

A prospective analysis of clinical and surgical records of patients operated in our Department with MIS SI joint with iFuse SI-Bone System (SI-BONE, Inc., San Jose, California, USA) between November 2009 and July 2013 was performed. Gender: 9 male/ 15 female, 11 cases bilaterally (all women). Age: $32-71$ years (mean 47.4 years). Height: 161-178 cm (mean $168.2 \mathrm{~cm}$ ). Weight: $56-84 \mathrm{~kg}$ (mean $68.4 \mathrm{~kg}$ )

Patients had a first out-patient's visit with clinical history taking and complete physical examination that included provocative maneuvers (Fröhling, Faber, Patrick, thigh thrust, distraction, compression, Gaenslen, sacral thrust and Yeoman tests) [21]. Patients were initially referred to the Department of Rheumatology. They took care of the patients with obvious pathology, such as ankylosing spondylitis, osteitis condensans ilii and sacroileitis. In case of doubt patients were also referred to the Department of Orthopedic Surgery. Those patients in whom no obvious SI joint pathology was found but in whom the SI joint pain continued to be a problem received antiinflammatory medication. If the pain was not well controlled with medication patients underwent an infiltration with local anesthetics and steroids (Figure 1). Patients underwent surgery only after failure of a minimum of 6 months conservative treatment with exhaustion of 
all non-operative treatment modalities (physical therapy, therapeutic injections, smoking cessation, anti-inflammatory medication, weight loss and chronic pain behavior treatment), and if the SI joint infiltration test had provided consistent relieve of the sacro-iliac joint pain. In case of doubt the infiltration was repeated up to three times. Those 24 patients that met all this criteria underwent percutaneous SI joint arthrodesis. The etiology was degenerative or spontaneous in 12 cases, previous fall on buttocks in 7 cases, coincident with a herniated lumbar disc in 3 cases and after postero-lateral fusion in 2 cases. Exclusion criteria: ankylosing spondylitis, osteitis condensans ilii and sacro-iliac joint arthropaty. Patients under these categories were handled by the Department of Rheumatology. Cases with associated lumbosacral pathology (2 cases) were not excluded provided the SI joint infiltration proved this joint to be the origin of the pain.

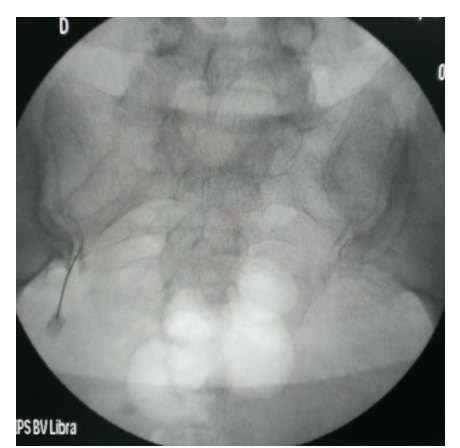

Figure 1: Sacroiliac joint therapeutic-diagnostic infiltration with steroids and anesthetics

Patients enrolled in this series only showed pain in the buttock and at times lumbar area. The pain sometimes radiated to the posterior aspect of the thigh. Pain was more intense on sitting and woke patients at night on attempting to turn over in bed. This is in contrast with the patients with lumbar sciatic pain that rest well on their side, on a fetal position. SI joint pain also gets worse while in the car, as any bumps in the road increase the pain, as well as pressing on the pedals of the vehicle while driving. The usual complain is the pain at night on turning over in bed and the limitation to drive a car. On clinical examination no signs of straight leg raising, muscle atrophy, sensory loss or osteo-tendinous reflexes loss were seen. The only possible confusion is with peri-trochanteric bursitis as patients also notice pain on lying on their sides but in this case turning over in bed and car driving is not painful at all. In the patients with previous lumbosacral surgeries it was common to see this area as a source of additional pain, but it could be distinguished on clinical examination grounds.

Demographics, reduction in analgesics and NSAID's, incidence and severity of complications, clinical outcome using a visual analog scale (VAS) for pain, Oswestry Disability Index (ODI) for back function and time to returning to work, were collected at one, three, six and 12 months after surgery and then at six months interval until last followup. The VAS is a known and validated [22] measurement instrument from one (no pain) to ten (worst pain ever) that results easy and fast to be applied. The ODI is an index that is derived from the Oswestry Low Back Pain Questionnaire used by clinicians and researchers to quantify disability for low back pain [23]. This tool is useful for measuring the degree of disability and estimating quality of life in a person with low back pain. The patient questionnaire contains topics concerning intensity of pain, lifting, ability to care for oneself, ability to walk, ability to sit, sexual function, ability to stand, social life, sleep quality, and ability to travel.

Changes in clinical outcome variables (VAS, ODI) were evaluated using a paired t-test using G-Stat program (version 2.0, Department of Biometrics GSK, Madrid) with a p-value threshold of 0.05 . We considered minimum clinically important difference thresholds for VAS pain and ODI improvement those reported in the Spine Patient Outcomes Research Trial (SPORT): $\geq 2$ points for VAS pain and $\geq 12.8$ for ODI [24].

\section{Surgical Technique}

Patients underwent a SI joint MIS percutaneous arthrodesis with the iFuse SI Joint Fusion System following the technique previously reported by others [11,25]. In essence devices are implanted in a lateral-to-medial direction across the diseased SI joint. Titanium implants are triangular in shape with porous plasma spray coating to minimize micro-motion and rotation. All surgeries were performed by the senior author (V.V-V). Pre-operatively each case was thoroughly studied (plain X-rays, MRI and CT-scan) to plan the desired implant trajectories and to account for possible anatomic variations. Procedures were performed under general anesthesia with the patient in prone position on a radiolucent table. We used two x-ray arches simultaneously, one for AP and one for lateral view, to locate anatomical landmarks (Figure 2).

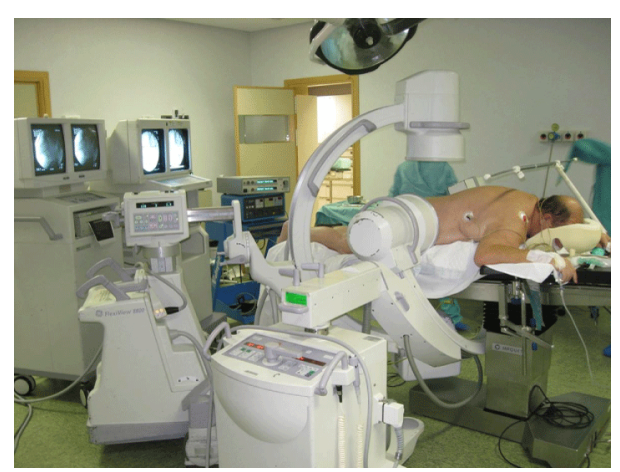

Figure 2: Surgical position with the patient in prone on a radiolucent table and using two $\mathrm{x}$-rays machines

Next, a small incision of about $2-3 \mathrm{~cm}$ was made in the skin (Figures 3 and 4). Lateral buttock and fascia were penetrated bluntly and the gluteus maximus muscle was split in the direction of its fibers to gain access to the outer table of the ilium. A sharp pointed Steinmann pin was placed through the ilium (Figure 5), around which the dilating tubes and the working channel was inserted. Then the Steinmann pin with a sharp tip was replaced by a blunt one. We have found this a vital step to prevent the sharp Steinmann pin to continue advancing while drilling, avoiding damages to the nearby nerve roots. The blunt pin is placed across the SI joint into the sacrum and lateral to the neural foramen (Figure 6). 
Citation: Vanaclocha VV, Verdú-López F, Sánchez-Pardo M, Gozalbes-Esterelles L, Herrera JM, et al. (2014) Minimally Invasive Sacroiliac Joint Arthrodesis: Experience in a Prospective Series with 24 Patients. J Spine 3: 185. doi:10.4172/2165-7939.1000185

Page 3 of 7

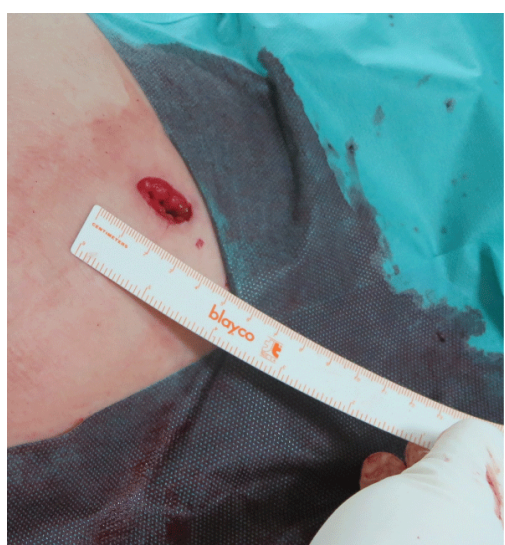

Figure 3: Surgical incision size

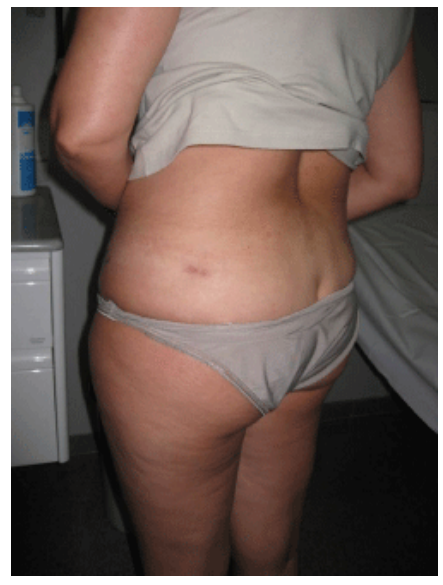

Figure 4: Good final cosmetic results

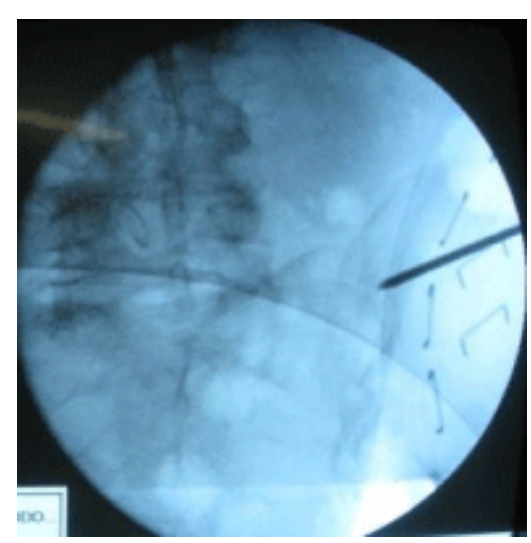

Figure 5: X-ray intraoperative image showing a Steinmann pin placed through the ilium

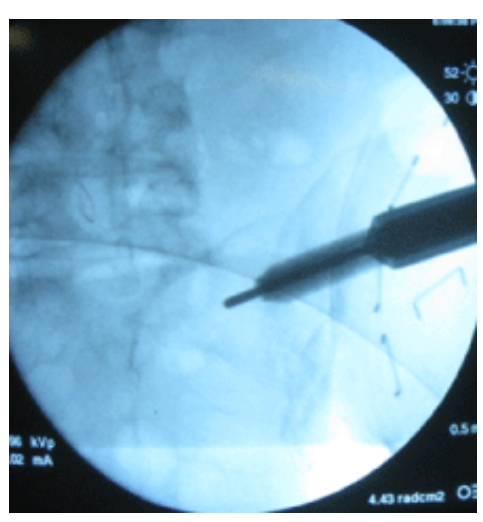

Figure 6: The Steinmann pin with a sharp tip is replaced by a blunt one and is placed across the SI joint. Surgical maneuvers are done through a cannulated tissue protector

To determine implant length, a depth gauge was used. Bone was prepared using a drill and triangular broach before the desired implant was inserted. All these maneuvers were done through a cannulated tissue protector. A pin-guide system is used to place the subsequent implants. The most cephalad implant is normally placed within the sacral ala. The second implant is usually located above or adjacent to the S1 foramen and the third between the S1 and S2 foramen, always respecting them (Figure 7).

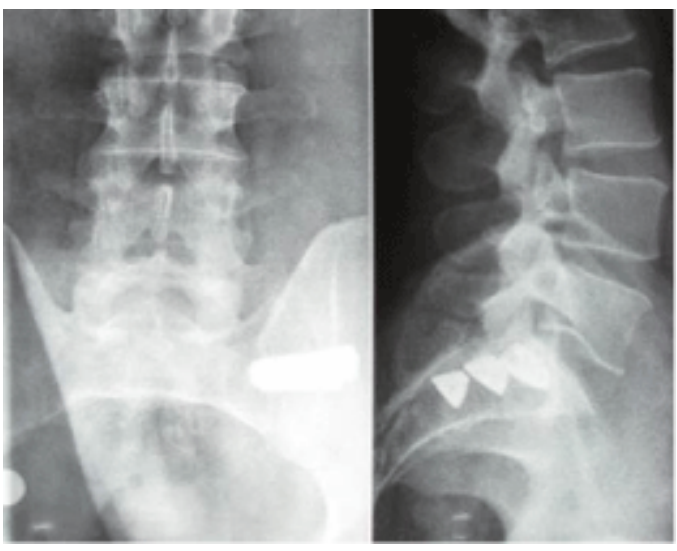

Figure 7: Lateral and anterior-posterior radiographs showing the definitive placement of the implants

During the whole procedure continuous monitorization using lateral, inlet, and outlet views on fluoroscopy was carried out. The incision is then copiously irrigated with saline and the tissue layers sequentially closed with absorbable sutures. Patients requiring treatment of both SI joints undergo bilateral arthrodesis in the same surgery.

Patients are discharged next day after surgery with progressive ambulation and activities. We cautioned against weight lifting, jumping and running, but patients were encouraged to walk daily short distances, morning and afternoon, increasing every day the distance they walked. Neither cane nor crutches were recommended. 
Citation: Vanaclocha VV, Verdú-López F, Sánchez-Pardo M, Gozalbes-Esterelles L, Herrera JM, et al. (2014) Minimally Invasive Sacroiliac Joint Arthrodesis: Experience in a Prospective Series with 24 Patients. J Spine 3: 185. doi:10.4172/2165-7939.1000185

Page 4 of 7

A follow-up visit was done at 1 month post-op and return to work was recommended in a stepwise fashion, particularly for those who needed driving or sitting for long periods. Heavy labor was discouraged for another month.

\section{Results}

Twenty-four patients were operated with iFuse SI-BONE technique from November 2009 till July 2013. 9 male/15 female, 11 cases bilaterally (all women). Age: 32-71 years (mean 47.4 years). Height: $161-178 \mathrm{~cm}$ (mean $168.2 \mathrm{~cm}$ ). Weight: $56-84 \mathrm{~kg}$ (mean $68.4 \mathrm{~kg}$ ). Preoperatively 3 patients were being treated with strong opioids (fentanyl patches), 4 with soft opioids (tramadol) and all of them were taking some sort of anti-inflammatory or analgesic medication (indometacin, naproxen, ibuprofen, paracetamol or metamizol).

Follow-up ranged from 1 to 4.5 years (mean 23.3 months). There were neither intraoperative nor postoperative major complications or need for blood transfusion. Mean estimated blood loss was $58 \mathrm{ml}$ (range $40-70 \mathrm{ml}$ ). Mean surgical time for unilateral cases 48 minutes (range 40-65 min). Bilateral cases took a similar time for each side but some 15 minutes in between were needed to re-arrange the $\mathrm{x}$-ray arches.

Four patients complained of immediate post-operative pain at the surgical site greater than the others, which responded well to medical therapy with anti-inflammatory medication. Local bruising was often seen with no further consequences but no local hematoma happened. During the first cases after using a sharp Steinmann pin all through the operation, there were two cases of temporary post-operative radiculopathic pain. After this we changed to a blunt Steinmann pin and since then there has been no other post-operative radiculopathic pain case. For the time being no failures of the device or other late complications have been observed. Post-op hospital stay was 1 day in all patients. The average time to returning to work was 47.4 days (range 30-67 days). Post-op patients showed a marked reduction in VAS scores and analgesic consumption (pre-op 8.7, one month postop 3.2, three months 2.8, six months post-op 2.1, 12 months post-op $1.7,18$ months 1.7 , at 2 years 1.9 , at 2 and $1 / 2$ years 1.8 , at 3 years 2.0 , at 3 and $1 / 2$ years 2.1 , at 4 years 2.1 and at 4 and a half years 2.1 ). Mean ODI scores improved from 54.1 preoperatively to $23.9,21.2,20.4$ and 14.3 at $1,3,6$ and 12 months postoperatively, remaining at $15.1,15.5$, $15.8,16.0,16.1,16.3$ and 16.3 at 1 and $1 / 2,2,2$ and $1 / 2,3,3$ and $1 / 2,4$ and 4 and $1 / 2$ years $(\mathrm{p}<.001)$. One year post-operatively no patient was taking opioids, 16 patients were not taking any drugs at all and 8 occasionally took some anti-inflammatory or analgesic. This occasional need for anti-inflammatory medication continued up to the latest follow-up. One year after surgery 22 of 24 patients responded positively stating that they would undergo the same procedure again. The two patients that had doubts were the two with a previous postero-lateral lumbar arthrodesis. Both reported much improvement in their pain but there was still some lumbar discomfort for which they felt unhappy.

In one female patient only two implants were inserted due to the small size of the SI joint but the clinical result was successful.

Quality of post-op images was good with no artifacts in MRI or CTscan (Figures 8 and 9).

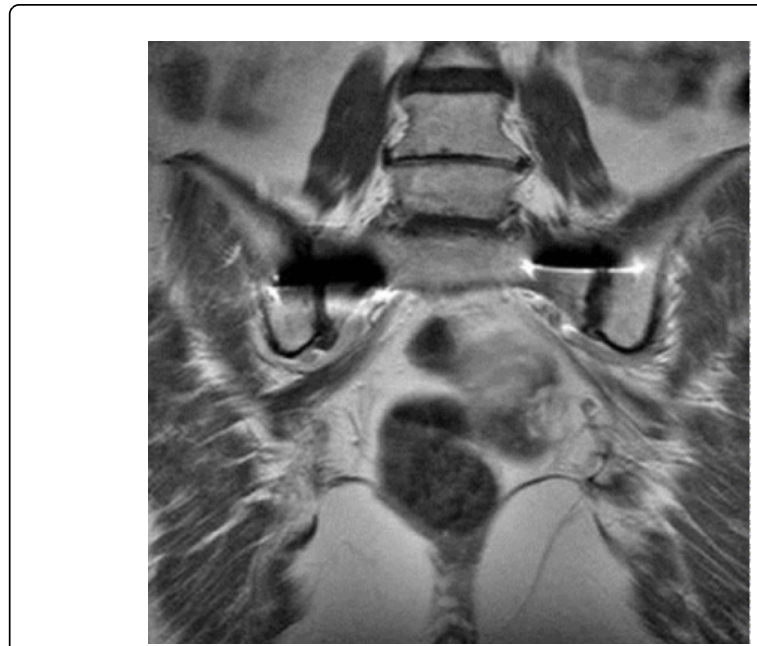

Figures 8: MRI and CT-scan postoperative images showing no problems of artifacts

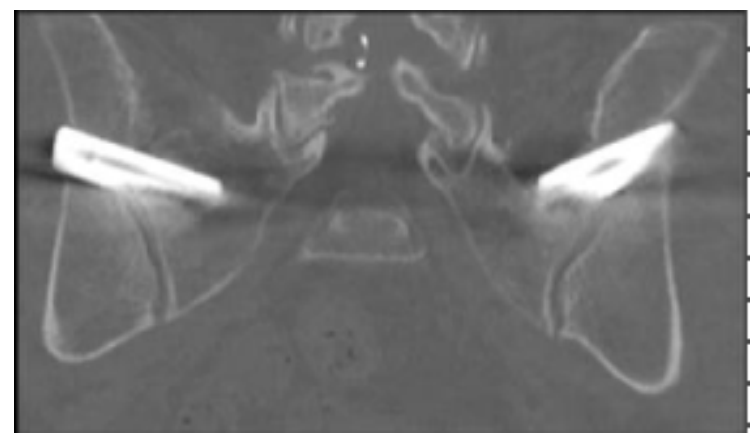

Figures 9: MRI and CT-scan postoperative images showing no problems of artifacts

We have not losses in the follow-up of the patients. There are not long-term complications and patients have remained clinically stable.

For the patient with concurrent lumbosacral pathology (two with postero-lateral fusion and three with lumbar disc prolapsed) results were different from the others. The worst possible scenario was the ones with a previous lumbar postero-lateral fusion. Both VAS and ODI scores were worse than in the rest of the group, mostly because the lumbar pain remained undisturbed in spite of improvement of the SI joint pain. In this specific group the VAS changed from pre-op 9,1, one month post-op 4.7, three months 4.6 , six months post-op 3.9, 12 months post-op 3.1, at 2 years 2.9 , at 3 years 3.0, at 4 years 3.1 and at 4 and a half years $3.4(\mathrm{p}<.001)$. Mean ODI scores improved from 58.8 preoperatively to $43.1,42.4,32.2$ and 24.3 at 1,36 and 12 months postoperatively, remaining at $25.5,25.8,26.2$ and 26.8 at $2,3,4$ and 4 and a half years $(\mathrm{p}<.001)$. The three patients with lumbar disc prolapsed both are still doing fine with minor problems but refuse any further treatment so far.

In the latest follow-up no patient that had undergone bilateral SI fusion (11 cases, all females) developed degenerative spondylolisthesis at the distal lumbo-sacral segments. 


\section{Discussion}

The SI joint is a pain generator in about $15 \%$ to $25 \%$ of axial low back pain patients [1]. Many patients with SI joint pain are misdiagnosed or not diagnosed at all, inducing a wrong treatment strategy that will lead to a bad result. It is therefore vital to be aware the kind of pain that originates from the SI joint as well as to diagnose and treat it accordingly. A recent systematic review shows that the evidence for the diagnostic accuracy of SI joint injections is good, the evidence for provocation maneuvers is fair, and evidence for imaging is limited [2].

A systematic evaluation of the therapeutic effectiveness of SI joint treatment modalities has shown that evidence was fair for cooled radiofrequency neurotomy and poor for short-term and long-term relief from intra-articular steroid injections, peri-articular injections of steroids or botullinum toxin, pulsed radiofrequency, and conventional radiofrequency neurotomy [3]. Unfortunately this review did not evaluate surgical treatment. Although in recent years good results have been reported with fusion of the SI joint [4-18], no clear-cut evidence has been published showing that surgery is superior to other treatment modalities and further comparative studies are needed $[19,20]$.

Since 1927 when Smith-Petersen described SI joint arthrodesis [26] several surgical series have been published. The first ones entailed opened approaches with large incisions, significant bone harvesting, lengthy hospital stays and restricted physical activity for several months. Results were acceptable but not too encouraging. Waisbrod et al. [4] in 1987 reported twenty-one patients treated with excision and package the SI joint with ceramic blocks and iliac crest bone graft, with satisfactory results in eleven of them and a $14 \%$ complication rate (2 pseudo-arthrosis and one infection). Keating et al. [27] in 1995 reported twenty-six patients treated with SI joint debridement, decortication and package with bone graft and secured with 2 lateral compression screws. No complications were seen, the pain scores decreased from 6.1 to 2.9 and there was improvement in work status. Later, in 1997, Moore [28] reported 77 patients treated with a modified Smith-Petersen technique. Through a $15 \mathrm{~cm}$ incision the cartilage of the SI joint was removed and the joint packed with autologous Ilium bone graft, kept in place with two to three cannulated screws. He reported successful results in 62 out of 77 patients $(80.5 \%)$ and a $13 \%$ complication rate (1 superficial wound infection, 1 post-op radicular pain, 1 sciatic notch fracture and 7 pseudo-arthrosis). Buchowski et al. [5] reported a similar technique in 20 patients but using instead a plate and screws to stabilize the graft. They achieved a solid fusion in 17 out of 20 patients with a return to work in 8 . Complication rate was $30 \%$ (3 pseudo-arthrosis, 2 deep wound infections, 1 painful hardware and 3 revision surgeries). Sixty percent of these patients stated that would undergo the surgery again.

Once proved that the surgical treatment can be a solution for those patients with pain refractory to conservative medical treatments, the next step was reduction in surgical aggressiveness with MIS techniques as these are widely established in the treatment of other lesions in other spinal locations [29,30]. Advantages are less morbidity, less postoperative pain, shorter hospital stay, better and faster recovery and earlier return to work. This may also result in economic benefits and reduced hospital costs.

Al-khayer et al. [7] and Wise et al. [8] published in 2008 their respective series with percutaneous techniques. The first group treated 9 patients with a $10 \mathrm{~mm}$ Hollow Modular Anchorage Screw packed with demineralized bone matrix across the SI joint and early mobilization in the post-op. They reported blood loss $<50 \mathrm{ml}$, hospital stay 6.9 days, ODI reduction from 59 to 45 , VAS improvement from 8.1 to 4.6 , no screw loosening, no screw failure, no nonunion and return to work in 4 out of 9 patients. They saw 1 deep wound infection and a complication rate of $11 \%$. Wise et al. treated 13 patients with $9 \mathrm{~mm}$ hole drilled through the longitudinal aspect of the SI joint and 2 cages packed with BMP placed across the anterior portion of it. Postop care entailed limited waist bending and sacral belt for 6 months with full activity at 6 months. Their results were: blood loss $<100 \mathrm{ml}$ per patient, length of stay: 1.7 days, fusion rate: $89 \%$, low back VAS improved 4.9 points and leg VAS 2.4 points. They reported a complication and revision rate of $8 \%$ with 1 reoperation (due to nonunion). In 2009 Khurana et al. [9] using the technique previously reported by Al-khayer et al. [7] reported 15 patients reducing the hospital stay to 2.7 days and with no complications.

In 2012 Rudolf [11] reported his results using the minimally invasive technique with triangular, porous plasma spray coated titanium implants. He treated 50 patients with early and sustained statistically significant improvement in pain function identified at all post-operative time points. A clinically significant improvement $(>2$ point change from baseline) was observed in 7 out of 9 domains of daily living. More than $80 \%$ of patients would have the same surgery again. There were, though, 10 peri-operative complications. Three patients with subcuticular skin closure developed superficial cellulitis that resolved after a short course of oral antibiotics. These infections never happened again after changing to Nylon skin sutures. One patient experienced a deep-soft tissue wound infection that resolved after 6 weeks of intravenous antibiotics. Two patients developed a large buttock hematoma, with post-operative pain and difficulty on sitting, resolving spontaneously in 4-6 weeks and leaving no residual symptoms. Implant penetration into the sacral neural foramen with nerve root irritation and radicular pain happened in two patients. Both were brought back to the OR and the misplaced implants retracted to the edge of the neural foramen with complete resolution of symptoms. Similarly, in one patient harboring an unrecognized hemi-sacralized L5 transitional vertebrae, the first implant was inadvertently placed too cephalad, compressing the L5 nerve. This patient needed a partial retraction of the implant too. Another patient suffered from a nondisplaced fracture located at the inferior edge of the ilium adjacent to the sciatic notch at the edge of the lowest implant but the fracture healed spontaneously and no further surgery was required. Finally, a late complication occurred three years after surgery. In a patient presenting persistent and gradually increasing SI joint pain the CT of the pelvis showed findings suggestive of motion surrounding the sacral end of the two most caudal implants. After a CT-guided injection confirming that the SI joint was the pain generator, two additional 7.0 $\mathrm{mm}$ implants were placed anteriorly to the loosened implants, resulting in complete symptom resolution. We believe that some of these complications in the Rudolf series are due to the learning curve of the technique and we profited from the advice received from him. We feel very grateful from the support and advice of this great master.

In the last two years more series with the iFuse SI Joint Fusion System have been published. Cummings et al. [12] have treated 18 patients without intraoperative complications and one explant at three months post-op due to malposition. All patient-reported outcomes showed both clinically and statistically significant improvement at 12 months. Duhon et al. [13] have reported the early results of a multicenter prospective single-arm cohort of patients. Mean subject age was 51 years ( $n=94$, safety cohort) and $66 \%$ of patients were women. Subjects were highly debilitated at baseline (mean VAS pain 
score 7.8, mean ODI score 54). There were no severe events devicerelated. Complete 6-month postoperative follow-up was available in 26 subjects. In the effectiveness cohort, mean SI joint pain improved from a baseline score of 7.8 to a 6 -month score of 2.9 , mean ODI improved from 55.3 to 38.9 and SF-36 PCS improved from 30.7 to 37.0. Ninety percent of subjects who were ambulatory at baseline regained full ambulation by 6 month post-op and median time to full ambulation was 30 days. Satisfaction with the procedure was high (85\%).

Miller et al. [16] have done an analysis of a post-market complaint database for the iFuse with 5319 patients that were treated between April 2009 and January 2013. Complaints were reported in 204 (3.8\%). Pain was the most commonly reported clinical complaint $(n=119$, $2.2 \%)$, with nerve impingement $(n=48,0.9 \%)$ and recurrent SI joint pain $(n=43,0.8 \%)$. All other clinical complaints were rare $(0.2 \%)$. They reported ninety-six revision surgeries performed in $94(1.8 \%)$ patients at a median follow-up of four (range 0-30) months. Revisions were typically performed in the early postoperative period for treatment of a symptomatic malpositioned implant $(\mathrm{n}=46,0.9 \%)$ or to correct an improperly sized implant in an asymptomatic patient $(\mathrm{n}=10,0.2 \%)$. Revisions in the late postoperative period were performed to treat symptom recurrence $(n=34,0.6 \%)$ or for continued pain of undetermined etiology $(n=6,0.1 \%)$.

Ledonio et al. [18] have compared 39 patients, of whom 22 underwent open and 17 underwent minimally invasive SI joint fusion and both resulted in statistically and clinically significant improvement for patients with degenerative SI pain refractory to nonoperative management. However, the number of patients reaching the minimally clinically important difference and those showing overall improvement were greater in the minimally invasive surgery group. The same author recently have published another paper [31] with 63 patients prospectively studied (open: 36; MIS: 27) who underwent SI joint fusion with minimum 1-year follow-up. Their results have shown that patients in the open group had a higher mean estimated blood loss $(681 \mathrm{ml}$ versus $41 \mathrm{ml}, \mathrm{p}<0.001)$. Mean surgical time and length of stay were shorter in the MIS group than in the open group (68 minutes versus 128 minutes and 3.3 days versus 2 days, $p<0.001$ for both). But with the numbers available, mean postoperative ODI scores were not different between groups ( $47 \%$ versus $54 \%, p=0.272$ ). They concluded that the study size was relatively small and it is possible that the study was underpowered.

We initially used a sharp Steinmann pin all through the operation, but after two cases of temporary post-operative radiculopathic pain, we decided to change to a blunt Steinmann pin. The sharp one is used to start with and set the dilators. Then it is removed and a blunt one is used to guide the drill, the broach and the implant insertion. Since then we have not seen any other case of post-op radiculopathic pain. Thus we strongly recommend it.

The results obtained in our series of patients are consistent with those published in the literature and support the use of percutaneous SI joint arthrodesis in carefully selected patients. This surgical approach offers less morbidity and therefore a better and faster recovery with less postoperative pain and less surgical stay with a faster return to work.

One of the weaknesses and limitations of the study is the small number of patients over a period of more than four years. This makes difficult to do the statistical analysis that could be no demonstrative. It is important to say that there are not long-term complications and patients have remained clinically stable with similar VAS and ODI over time.

\section{Conclusions}

SI joint pain can be the cause of low back pain in a significant number of patients. It is vital to be aware of the SI joint as a pain generator in order to diagnose and treat it. Treatment should be carried out in stages from low to high aggressiveness according to patient response. A small subset of all patients with lumbo-sacral pain will ultimately require an arthrodesis of the SI joint. Percutaneous SI joint arthrodesis can be an effective and safe treatment modality in patients with chronic and well-diagnosed SI joint pain.

\section{References}

1. Cohen SP (2005) Sacroiliac joint pain: a comprehensive review of anatomy, diagnosis, and treatment. Anesth Analg 101: 1440-1453.

2. Simopoulos TT, Manchikanti L, Singh V, Gupta S, Hameed H, et al. (2012) A systematic evaluation of prevalence and diagnostic accuracy of sacroiliac joint interventions. Pain Physician 15: E305-344.

3. Hansen H, Manchikanti L, Simopoulos TT, Christo PJ, Gupta S, et al. (2012) A systematic evaluation of the therapeutic effectiveness of sacroiliac joint interventions. Pain Physician 15: E247-278.

4. Waisbrod H, Krainick JU, Gerbershagen HU (1987) Sacroiliac joint arthrodesis for chronic lower back pain. Arch Orthop Trauma Surg 106: 238-240.

5. Buchowski JM, Kebaish KM, Sinkov V, Cohen DB, Sieber AN, et al. (2005) Functional and radiographic outcome of sacroiliac arthrodesis for the disorders of the sacroiliac joint. Spine J 5: 520-528.

6. Schütz U, Grob D (2006) Poor outcome following bilateral sacroiliac joint fusion for degenerative sacroiliac joint syndrome. Acta Orthop Belg 72: 296-308.

7. Al-Khayer A, Hegarty J, Hahn D, Grevitt MP (2008) Percutaneous sacroiliac joint arthrodesis: a novel technique. J Spinal Disord Tech 21: 359-363.

8. Wise CL, Dall BE (2008) Minimally invasive sacroiliac arthrodesis: outcomes of a new technique. J Spinal Disord Tech 21: 579-584.

9. Khurana A, Guha AR, Mohanty K, Ahuja S (2009) Percutaneous fusion of the sacroiliac joint with hollow modular anchorage screws: clinical and radiological outcome. J Bone Joint Surg Br 91: 627-631.

10. McGuire RA, Chen Z, Donahoe K (2012) Dual fibular allograft dowel technique for sacroiliac joint arthrodesis. Evid Based Spine Care J 3: 21-28.

11. Rudolf L (2012) Sacroiliac Joint Arthrodesis-MIS Technique with Titanium Implants: Report of the First 50 Patients and Outcomes. Open Orthop J 6: 495-502.

12. Cummings J Jr, Capobianco RA (2013) Minimally invasive sacroiliac joint fusion: one-year outcomes in 18 patients. Ann Surg Innov Res 7: 12.

13. Duhon BS, Cher DJ, Wine KD, Lockstadt H, Kovalsky D, et al. (2013) Safety and 6-month effectiveness of minimally invasive sacroiliac joint fusion: a prospective study. Med Devices (Auckl) 6: 219-229.

14. Kim JT, Rudolf LM, Glaser JA (2013) Outcome of percutaneous sacroiliac joint fixation with porous plasma-coated triangular titanium implants: an independent review. Open Orthop J 7: 51-56.

15. Sachs D, Capobianco R (2013) Minimally invasive sacroiliac joint fusion: one-year outcomes in 40 patients. Adv Orthop 2013: 536128.

16. Miller LE, Reckling WC, Block JE (2013) Analysis of postmarket complaints database for the iFuse SI Joint Fusion System ${ }^{\circ}$ : a minimally invasive treatment for degenerative sacroiliitis and SI joint disruption. Med Devices (Auckl) 6: 77-84.

17. Gaetani P, Miotti D, Risso A, Bettaglio R, Bongetta D, et al. (2013) Percutaneous arthrodesis of sacro-iliac joint: a pilot study. J Neurosurg Sci 57: 297-301. 
Citation: Vanaclocha VV, Verdú-López F, Sánchez-Pardo M, Gozalbes-Esterelles L, Herrera JM, et al. (2014) Minimally Invasive Sacroiliac Joint Arthrodesis: Experience in a Prospective Series with 24 Patients. J Spine 3: 185. doi:10.4172/2165-7939.1000185

Page 7 of 7

18. Ledonio CG, Polly DW Jr, Swiontkowski MF, Cummings JT Jr (2014) Comparative effectiveness of open versus minimally invasive sacroiliac joint fusion. Med Devices (Auckl) 7: 187-193.

19. Ashman B, Norvell DC, Hermsmeyer JT (2010) Chronic sacroiliac joint pain: fusion versus denervation as treatment options. Evid Based Spine Care J 1: 35-44.

20. Spiker WR, Lawrence BD, Raich AL, Skelly AC, Brodke DS (2012) Surgical versus injection treatment for injection-confirmed chronic sacroiliac joint pain. Evid Based Spine Care J 3: 41-53.

21. Szadek KM, van der Wurff P, van Tulder MW, Zuurmond WW, Perez RS (2009) Diagnostic validity of criteria for sacroiliac joint pain: a systematic review. J Pain 10: 354-368.

22. Knop C, Oeser M, Bastian L, Lange U, Zdichavsky M, et al. (2001) [Development and validation of the Visual Analogue Scale (VAS) Spine Score]. Unfallchirurg 104: 488-497.

23. Fairbank JC, Pynsent PB (2000) The Oswestry Disability Index. Spine (Phila Pa 1976) 25: 2940-2952.

24. Copay AG, Glassman SD, Subach BR, Berven S, Schuler TC, et al (2008) Minimum clinically important difference in lumbar spine surgery patients: a choice of methods using the Oswestry disability index, medical outcomes study questionnaire short form 36 , and pain scales. Spine J 8 : 968-974.
25. Geisler F (2013) Stabilization of the sacroiliac joint with the SI-bone surgical technique. Neurosurg Focus 35: Video 8.

26. Smith-Petersen MN (1921) Arthrodesis of the SI joint. A new method of approach. J Bone Joint Surg Am 3: 400-405.

27. Keating J, Sims V, Avillar M (1995) SI joint fusion in a chronic low back pain polpulation. The integrated function of the lumbar spine and SI joint. Rotterdam: ECO pp. 361-365.

28. Moore MR (1997) Surgical treatment of chronic painful SI joint dysfunction. Movement, stability, and low back pain: the essential role of the pelvis. New York: Churchill Livingstone pp. 563-572.

29. Verdú-López F, Beisse R (2014) Current status of thoracoscopic surgery for thoracic and lumbar spine. Part 2: treatment of the thoracic disc hernia, spinal deformities, spinal tumors, infections and miscellaneous. Neurocirugia (Astur) 25: 62-72.

30. Verdú-López F, Vanaclocha-Vanaclocha V, Gozalbes-Esterelles L, Sánchez-Pardo M (2014) Minimally invasive spine surgery in spinal infections. J Neurosurg Sci 58: 45-56.

31. Ledonio CG, Polly DW Jr, Swiontkowski MF (2014) Minimally invasive versus open sacroiliac joint fusion: are they similarly safe and effective? Clin Orthop Relat Res 472: 1831-1838. 